BMJ Open Ophthalmology

\title{
Ocular manifestations of RT-PCR- confirmed COVID-19 cases in a large database cross-sectional study
}

\author{
Deepayan Sarkar, ${ }^{1}$ Deepak Soni (1),${ }^{1}$ Aniza Nagpal, ${ }^{1}$ Fazil Khurram, ${ }^{1}$ \\ Samendra Karkhur (D) , ${ }^{1}$ Vidhya Verma, ${ }^{1}$ Rajiv R Mohan (D) , ${ }^{2}$ Bhavana Sharma (D) ${ }^{1}$
}

To cite: Sarkar D, Soni D, Nagpal A, et al. Ocular manifestations of RTPCR-confirmed COVID-19 cases in a large database cross-sectional study. BMJ Open Ophthalmology 2021;6:e00775. doi:10.1136/ bmjophth-2021-000775

DSa and DSo contributed equally.

DSa and DSo are joint first authors.

Received 30 March 2021 Accepted 21 August 2021

A) Check for updates

(C) Author(s) (or their employer(s)) 2021. Re-use permitted under CC BY-NC. No commercial re-use. See rights and permissions. Published by BMJ.

${ }^{1}$ Department of Ophthalmology, All India Institute of Medical Sciences, Bhopal, Madhya Pradesh, India

${ }^{2}$ Department of Ophthalmology, College of Veterinary Medicine and Mason Eye Institute, School of Medicine, University of Missouri, Columbia, Missouri, USA

Correspondence to Dr Bhavana Sharma; head. ophtho@aiimsbhopal.edu.in

\section{ABSTRACT}

Objective To evaluate ocular manifestations of reverse transcriptase (RT)-PCR-confirmed SARS-CoV-2-infected patients in a validated comparative model, and additionally to evaluate the correlation between severity of COVID-19 and ocular manifestations.

Methods and Analysis In a prospective crosssectional study, a total of 2400 subjects were enrolled over a period of 8 months. To eliminate bias of identical ocular symptom profile in other non-COVID-19 respiratory infections and to acquire a comparative model, 1200 COVID-19 RT-PCR-positive patients (group 1) and 1200 RT-PCR-negative patients (group 2) were included. Data collection included use of a prestructured tool and 'Googleforms', along with stratification of patients into 'mild, moderate, and severe' categories. Study subjects were evaluated for ocular manifestations by clinical examination and laboratory work-up. Univariate and multivariate logistic regression analyses were performed.

Results $144(12 \%)$ patients in group 1 had ocular symptoms as compared with $24(2 \%)$ patients in group 2 ( $p<0.001)$. Ocular manifestations (symptoms and signs) comprising burning sensation $(6.7 \%, p<0.001)$, foreign body sensation and irritation $(7.0 \%, p<0.001)$, and conjunctival signs $(2.7 \%, p<0.001)$ were found statistically significant in group 1 as compared with group 2. Ocular involvement increased in proportion to severity of COVID-19: mild (5.3\%), moderate $(24.6 \%)$ and severe $(58.8 \%)(p=0.0006)$.

Conclusion The frequency of occurrence of ocular manifestations was higher in group 1 as opposed to group 2. Furthermore, the presence of ocular manifestations carried a direct correlation with severity of systemic disease and presence of comorbidities.

\section{INTRODUCTION}

SARS-CoV-2, commonly known as "coronavirus', belongs to Family Coronaviridae, Order Nidovirales with characteristic prominent spikes on its envelope. ${ }^{1}$ It is an enveloped, single-stranded, positive-sense RNA, novel beta-coronavirus. ${ }^{1}$ Virus genome sequences obtained directly from patients' body fluids or cultured viruses from hospitalised patients with pneumonia showed the aetiological agent to be a beta-coronavirus belonging to a new class in the subgenus Sarbecovirus of the

\section{Key messages}

What is already known about this subject?

- Several studies have reported the characteristic ocular manifestations of SARS-CoV-2 infection, yet there is a gap in our understanding of the ocular manifestations of COVID-19.

- The reported ocular manifestations of the infection vary greatly, from conjunctival congestion, ophthalmoplegia and dry eye, to blurring of vision and retinal/macular involvement, as per various case reports and small database studies.

\section{What are the new findings?}

- The study demonstrates the incidence of ocular signs and symptoms among patients with SARSCoV-2 infection in a large database comparative model.

- Furthermore, the study shows that the incidence of ocular manifestations in patients with COVID-19 increases with severity of the disease and has a positive correlation with increasing age and systemic comorbidities.

\section{How might these results change the focus of research or clinical practice?}

This study helps establish the fact that ocular manifestations in the form of ocular surface inflammation are frequently found in patients with COVID-19 and could be the initial symptom.

- No substantial evidence is available yet regarding the timing of appearance of SARS-CoV-2 in the conjunctival epithelium and tears.

- This knowledge is not only essential among frontline workers but also substantiates the need for further studies to assess transmissibility by ocular route in early cases and most importantly in asymptomatic patients with COVID-19.

Orthocoronavirinae subfamily. ${ }^{2}$ The transmission occurs mainly via aerosols, while disease presentation involves influenza-like symptoms such as cough, sore throat, rhinorrhoea, fever or breathlessness. Recent studies have shown the spread of coronavirus through air in indoor settings. ${ }^{3}$ The incubation period of COVID-19 ranged from 2 to 14 days. ${ }^{4}$ 
As reported by the WHO, ${ }^{5}$ the first COVID-19 case was detected in the city of Wuhan in China on 31 December 2019. The infection has since spread worldwide. According to the WHO, ${ }^{5}$ as of 30 May 2021 there have been 169118995 confirmed cases of COVID-19 globally, including 3519175 deaths. In India alone, there have been 27894800 positive COVID-19 cases, with 325972 deaths. ${ }^{6}$ Globally, India is the second highest affected country with high transmission rates. ${ }^{5}$

There is an ever-increasing pool of data concerning its pathophysiology, disease presentation, transmission, organs affected and treatment. A report published by WHO on 15 September 2020 states that $80 \%$ of the cases remain asymptomatic and do not require hospitalisation. ${ }^{2}$ However severe cases may develop progressive respiratory failure that potentially leads to death. Cases were classified into mild, moderate and severe as per the 'Clinical Management Protocol - COVID-19'.

Coronavirus has been shown to cause severe ocular manifestations in animals, including anterior uveitis, vasculitis and optic neuritis in feline and murine species. ${ }^{8}$ However, ocular manifestations in humans are mild and have been previously reported to vary from $2 \%$ to $32 \%$. Currently, there is no clear consensus on the ocular manifestations of COVID-19 owing to the paucity of comparative studies with large sample sizes.

The present study intends to evaluate the ocular manifestations of reverse transcriptase (RT)-PCR-confirmed patients with COVID-19 in a validated comparative model. Additionally, an attempt was made to evaluate correlations, if any, between ocular involvement and severity of COVID-19, in addition to ocular manifestations and presence of comorbidities, among cases who tested positive.

\section{METHODS}

\section{Study design}

This was a prospective, cross-sectional, single-centre study conducted at a tertiary referral institute in Central India. The study was conducted over a period of 8 months between March and October 2020. The primary objective of the study was to evaluate ocular manifestations in patients with COVID-19 and to compare them with patients who tested negative. The secondary objective was to identify an association, if any, between ocular involvement and severity of systemic COVID-19.

RT-PCR-positive COVID-19 cases were enrolled in group 1, while negative cases were enrolled in group 2, as per the Indian Council of Medical Research (ICMR) criteria. $^{9}$

Previous studies have shown mild ocular symptoms in non-COVID-19 respiratory infections. ${ }^{10}{ }^{11}$ Therefore COVID-19-negative patients were also included to eliminate bias of similar ocular symptom profile in other non-COVID-19 respiratory infections. To ensure equal participation of patients in both groups, along with the inclusion of a positive patient, the next consecutively registered negative patient was enrolled. A comparative model was chosen to eliminate bias of similar ocular symptom profile in other non-COVID-19 respiratory infections.

\section{Inclusion criteria}

- Patients presenting with symptoms of acute respiratory infection and subjected to RT-PCR test for SARS-CoV-2.

- Patients who gave consent for participation in the study.

\section{Exclusion criteria}

- Patients with pre-existing ocular conditions such as allergic conjunctivitis, corneal diseases such as keratitis, corneal dystrophies, dry eye disease, and any other ocular surface disorder, in addition to patients on any topical medication at the time of presentation were excluded from the study.

\section{Sample size calculation and technique}

The sample size was calculated using the formula $\mathrm{n}=\mathrm{z}^{2} \mathrm{pq} / \mathrm{d}$, where $\mathrm{n}=$ sample size, $\mathrm{z}=$ value of standard normal variate at 0.05 level of significance (1.96), $\mathrm{p}=\mathrm{prev}$ alence of ocular manifestations in COVID-19 (31.6\%), $\mathrm{q}=100-\mathrm{p}$ and $\mathrm{d}=$ allowable error $(5 \%)$. The minimum sample size calculated was 346, and after adjusting for a $10 \%$ non-response rate the final minimum sample size was calculated to be 392 . For group 1 'simple random sampling' was done, while for group 2 'convenience sampling' was done. A total of 2400 subjects (4800 eyes), comprising 1200 patients (2400 eyes) in the COVID-19positive group (group 1) and 1200 patients (2400 eyes) in the COVID-19-negative group (group 2), were enrolled. However, in agreement with instated statistical methods, we would be describing study subjects $(\mathrm{N}=2400)$ for data evaluation and presentation.

\section{Patient and public involvement}

Patients or the public were not involved in the design, conduct, reporting or dissemination of our research.

\section{Data collection}

A prestructured tool was used to collect information regarding demographic details (name, age, gender and residential address), chief complaints, ocular signs and symptoms, systemic comorbidity, previous medical records and RT-PCR test results. The particulars were noted in the predesigned proforma in 'Google-forms', along with severity grading into mild, moderate or severe as per clinical symptoms.

Study subjects were evaluated for ocular involvement by routine clinical and laboratory work-up as per standard institutional protocols and guidelines issued by the ICMR and the Ministry of Health, Government of India. ${ }^{9}$ Participants gave written informed consent to participate before enrolment in the study.

\section{Ocular examination}

Documentation of ocular manifestations if present was done when the patient presented for screening, or when 
symptoms subsequently developed during the hospital stay, at the time of follow-up or at 1 month, whichever was longer.

\section{Follow-up}

COVID-19-positive cases with ocular symptoms in group 1 were treated as per the clinical profile. Group 2 (control) subjects were initially examined during presentation and followed up as per the study protocol and the ocular complaints were treated symptomatically. The prevalence of ocular symptoms in groups 1 and 2 was compared to evaluate whether the ocular symptoms were due to COVID-19 infection or due to non-COVID-19 upper respiratory infection, raising the suspicion for COVID-19 infection in a patient.

Cases were followed up during their hospital stay to identify the appearance of new signs or resolution of already existing ones. This was done on enrolment and at day 1, day 3, 1 week, 2 weeks and 1 month from the day of admission. In the event of discharge from the hospital before completion of 1 month, patients were followed up subsequently as outpatients in our clinics.

\section{Data entry and statistical analysis}

The collected data were transformed into variables and then coded and entered in Microsoft Excel. Data were analysed and statistically evaluated using SPSS software, V.PC-23.

Qualitative data were expressed in percentage. Statistical differences between proportions were tested by $\chi^{2}$ test or Fisher's exact test. A p value of less than 0.05 was considered statistically significant for all the results. Univariate analysis was performed and factors which were found significant were entered in a multivariate logistic regression analysis.

\section{RESULTS}

A total of 2400 eyes of 1200 patients in each group were evaluated. In group 1, majority of the participants were in the $19-45$ years age range $(52.6 \%)$, followed by $46-65$ years $(30.5 \%)$. Of the patients $9.7 \%$ were $>65$ years, while $7.2 \%$ were younger than 18 years of age. In group 2, majority of the subjects $(67.7 \%)$ were in the $19-45$ years age groups. In group 1, the incidence of ocular manifestations was found higher in the elderly, that is, age $>65$ years, and least among patients in the 19-45 years age group (table 1).

In comparison with 144 (12\%) patients in group 1, only $24(2 \%)$ patients in group 2 developed ocular manifestations, the result being statistically significant $(\mathrm{p}<0.001)$ (table 2).

Burning sensation in the eyes was present in 80 (6.7\%) patients in group 1 as compared with $16(1.3 \%)$ in group 2 and this was statistically significant $(\mathrm{p}<0.001)$. Likewise, $84(7 \%)$ patients in group 1 had foreign body sensation and eye irritation compared with $4(0.3 \%)$ in group 2 $(\mathrm{p}<0.001)$. Of the total patients, $32(2.7 \%)$ in group 1 had redness of the eyes as compared with $4(0.3 \%)$ in

\begin{tabular}{|c|c|c|c|}
\hline \multirow[b]{2}{*}{$\begin{array}{l}\text { Age group } \\
\text { (years) }\end{array}$} & \multicolumn{2}{|c|}{ Ocular manifestations } & \multirow[b]{2}{*}{$\begin{array}{l}\text { Total } \\
\text { n (\%) }\end{array}$} \\
\hline & $\begin{array}{l}\text { Present } \\
\mathrm{n}(\%)\end{array}$ & $\begin{array}{l}\text { Absent } \\
\mathrm{n}(\%)\end{array}$ & \\
\hline \multicolumn{4}{|l|}{ Group 1} \\
\hline $1-18$ & $6(6.9)$ & 81 (93.1) & $87(7.2)$ \\
\hline $19-45$ & 80 (12.7) & 551 (87.3) & $631(52.6)$ \\
\hline $46-65$ & 37 (10.3) & 322 (89.7) & 359 (30.5) \\
\hline$>65$ & $21(17.1)$ & 102 (82.9) & $123(9.7)$ \\
\hline \multicolumn{4}{|l|}{$P=0.09$} \\
\hline \multicolumn{4}{|l|}{ Group 2} \\
\hline $1-18$ & $2(1.5)$ & $129(98.5)$ & 131 (10.9) \\
\hline $19-45$ & $15(1.8)$ & 797 (98.2) & $812(67.7)$ \\
\hline 46-65 & $5(2.3)$ & 216 (97.7) & $221(18.4)$ \\
\hline$>65$ & $2(5.6)$ & $34(94.4)$ & $36(3.0)$ \\
\hline$P=0.44$ & & & \\
\hline
\end{tabular}

group 2 and this was statistically significant $(\mathrm{p}<0.001)$ (table 2).

On ocular examination, conjunctival congestion was seen in $32(2.7 \%)$ patients in group 1 as compared with $4(0.3 \%)$ patients in group 2 and the association was found to be statistically significant $(\mathrm{p}<0.001)$. No other finding was noted during detailed examination of the ocular adnexa and anterior segment (table 2). Posterior segment evaluation in both groups did not reveal any significant findings.

Out of 1200 patients in group 1, 552 (46\%) presented without any symptoms of COVID-19. However, in the remaining 648 (54\%) patients who tested positive, fever was the most common presentation, which was seen in 288 (24\%) subjects. Patients were stratified into mild, moderate and severe category depending on the frequency and severity of the systemic features. ${ }^{7}$

With reference to ocular manifestations as a correlate to the severity of systemic illness, $5.3 \%, 25.6 \%$ and $58.8 \%$ of patients with mild, moderate and severe COVID-19 symptoms, respectively, presented with ocular manifestations (figure 1). These findings suggested that ocular involvement increased in proportion to the severity of COVID-19 and the association was found to be statistically significant ( $\mathrm{p}=0.0006$ ) (figure 1$)$. The factors found significant on bivariate analysis were subjected to multivariate logistic regression for adjustment and to control the effect of confounding variables. The odds of developing ocular manifestations in group 1 were 6.460 times higher when compared with group 2. This association was found to be highly significant on multivariate analysis (table 3).

In patients without systemic comorbidities, $9.6 \%$ in group 1 developed ocular manifestations as compared with $1.8 \%$ in group 2. Furthermore, the odds of presenting with or developing ocular manifestations in 
Table 2 Ocular manifestations in study groups

\begin{tabular}{|c|c|c|c|c|c|}
\hline \multicolumn{2}{|l|}{ Variable } & $\begin{array}{l}\text { Total } \\
\text { n (\%) } \\
(\mathrm{N}=2400)\end{array}$ & $\begin{array}{l}\text { Group } 1 \\
n(\%) \\
(n=1200)\end{array}$ & $\begin{array}{l}\text { Group } 2 \\
n(\%) \\
(n=1200)\end{array}$ & $P$ value \\
\hline \multicolumn{2}{|c|}{ Ocular manifestations } & $168(7)$ & $144(12.0)$ & $24(2.0)$ & $<0.001$ \\
\hline \multirow[t]{3}{*}{ Symptoms } & Burning sensation of eyes & $96(4.0)$ & $80(6.7)$ & $16(1.3)$ & $<0.001$ \\
\hline & Redness of eyes & $36(1.5)$ & $32(2.7)$ & $4(0.3)$ & $<0.001$ \\
\hline & Foreign body sensation and irritation of eyes & $88(3.7)$ & $84(7.0)$ & $4(0.3)$ & $<0.001$ \\
\hline \multirow[t]{3}{*}{ Signs } & Lid and adnexa signs & $0(0.00)$ & $0(0.00)$ & $0(0.00)$ & - \\
\hline & Conjunctival signs & $36(1.5)$ & $32(2.7)$ & $4(0.3)$ & $<0.001$ \\
\hline & Corneal signs & $0(0.00)$ & $0(0.00)$ & $0(0.00)$ & - \\
\hline
\end{tabular}

group 1 were 2.019 times higher in patients with systemic comorbidities (hypertension, diabetes, cardiovascular diseases, thyroid dysfunction or asthma), as against those without systemic comorbidities. However, the association was not found to be statistically significant (table 4).

While evaluating the association between the frequency of ocular manifestations and the age of patients, it was seen that patients in group 1 in the $>65$ years age group were at greater odds of developing ocular manifestations, although this was statistically not significant $(\mathrm{p}=0.09)$ (table 1). The results were insignificant for similar correlation drawn among patients in group 2 (table 1 ).

\section{DISCUSSION}

SARS-CoV-2 is mainly associated with respiratory infection and subsequent respiratory failure in severe cases. ${ }^{12}$ Thus, a majority of epidemiological studies, diagnostic and therapeutic efforts are justifiably targeted towards the consequences of respiratory tract infection and its prevention. Nevertheless, it is important to be appraised of other systemic and local manifestations of the disease and its consequences, principally to identify alternative ways of transmission if any and provide adequate and timely intervention to thwart potential complications.

The results of our study shows that the most commonly affected age group of patients were young adults (19-45 years), quite similar to previous observations by Gupta $e t$ $a l .{ }^{13}$ The preponderance of younger age group can be

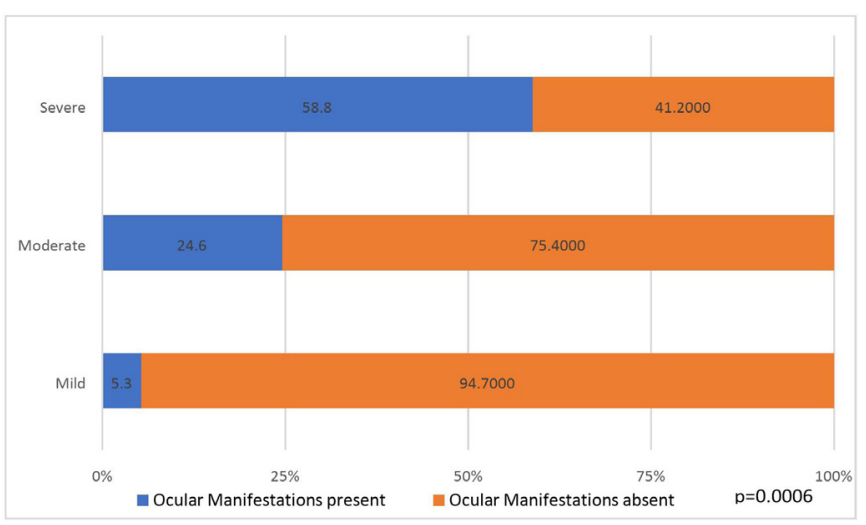

Figure 1 Association between COVID-19 severity and ocular manifestations $(n=1200, p=0.0006)$. attributed to the demographic distribution of the population. Additionally, it may also be attributed to the higher work and travel-related exposure in this group.

Ocular manifestations in COVID-19 have been reported by various authors, ${ }^{1}$ although with a limited sample size, mainly in case series and retrospective studies. Further, ocular manifestations that correlated with disease severity have been demonstrated only in small case series and thus short of presenting any conclusive evidence on the overall incidence, clinical correlation and progression (table 5). ${ }^{14-21}$

The ocular manifestations of SARS-CoV-2 as reported previously by various authors are conjunctival hyperaemia, chemosis, follicular conjunctivitis, epiphora, watery discharge, eyelid oedema, and enlarged preauricular and submaxillary lymph nodes. ${ }^{22}$ Epiphora as a presenting symptom of COVID-19 has also been previously reported. ${ }^{22}$ Therefore, ophthalmologists may be among the first to evaluate and inform about the possible diagnosis of COVID-19. Cheema et $a t^{23}$ have reported one case with unilateral keratoconjunctivitis as the first manifestation of COVID-19, while another study described bilateral pseudomembranous conjunctivitis in an intubated patient who was successfully treated with azithromycin eye-drops, low doses of dexamethasone and mechanical debridement. ${ }^{24}$

The current study brings out a detailed evaluation of ocular manifestations in a large sample size and its correlation with age, disease severity and other comorbidities. Ocular manifestations as noted in our study mainly comprised ocular surface inflammation. Inflammation or infection of the conjunctiva is known as conjunctivitis and is characterised by dilatation of the conjunctival vessels, resulting in hyperaemia and oedema of the conjunctiva, typically with associated discharge. ${ }^{25}$ Non-specific symptoms include lacrimation, grittiness or foreign body sensation, stinging, and burning sensation. ${ }^{26}{ }^{27}$ To identify these non-specific symptoms in the absence of conjunctival signs would be more suggestive of a diagnosed or latent dry eye disease. However, conjunctival inflammation was not attributed to dry eye disease, as per the median duration of ocular manifestations of 3 (2-5) days, self-limiting course and absence of substantial 
Table 3 Logistic regression analysis for determinants of ocular manifestations

\begin{tabular}{|c|c|c|c|c|c|c|}
\hline \multirow[b]{2}{*}{ Variable } & \multirow[b]{2}{*}{ B } & \multirow[b]{2}{*}{ SE } & \multirow[b]{2}{*}{ Significance } & \multirow[b]{2}{*}{$\operatorname{Exp}(B)$} & \multicolumn{2}{|c|}{$95 \% \mathrm{Cl}$ for $\operatorname{Exp}(\mathrm{B})$} \\
\hline & & & & & Lower & Upper \\
\hline \multicolumn{7}{|c|}{ COVID-19 status } \\
\hline Positive & 1.866 & 0.227 & 0.000 & 6.460 & 4.13 & 10.08 \\
\hline Negative & Reference & & & & & \\
\hline \multicolumn{7}{|l|}{ Comorbidity } \\
\hline Present & 0.746 & 0.172 & 0.000 & 2.019 & 1.505 & 2.956 \\
\hline Absent & Reference & & & & & \\
\hline Age in years & 0.002 & 0.005 & 0.644 & 0.998 & 0.989 & 1.007 \\
\hline
\end{tabular}

evidence of dry eye disease at 1-month follow-up visit among subjects. Furthermore, in the absence of conjunctival signs in a few of the subjects with these symptoms, as per standard definition, we have attributed the presenting features to ocular surface inflammation rather than conjunctivitis. There were no cases with severe involvement and vision-threatening complications or posterior segment manifestations during the study period, even in patients with severe COVID-19 systemic infection.

During the COVID-19 outbreak, conjunctivitis has been reported as one of the definitive ocular manifestations with viral RNA isolated from tears. ${ }^{18} 28$ The incidence of conjunctivitis as reported by various authors ranges between $0.89 \%$ and $31.6 \%$ (table 5). Previous severe acute respiratory syndrome pandemics have also reported conjunctival involvement in the form of congestion, with watering. ${ }^{29}$ These observations favour conjunctivitis as being the most common ophthalmic manifestation and having the maximum likelihood of being present in SARS-CoV-2 infection. ${ }^{30}$ Our study, comprising a large prospective database of patients with varying demographics, severity and comorbidities, reports an incidence of conjunctivitis of 2.7\% in COVID-19-positive patients (group 1) as opposed to an incidence of $0.3 \%$ in negative cases (group 2), which is statistically significant. This could be attributed to a stronger immune response and subsequent inflammatory reaction in COVID-19 as compared with other viral illnesses. Also, of all positive cases, $12 \%$ had ocular symptoms, with the most common symptom being burning sensation in the eyes, followed by redness, irritation and foreign body sensation.

Previous studies have suggested that conjunctivitis may be the first manifestation of this disease, followed by the onset of systemic symptoms after a variable time period. ${ }^{29}$ Other workers have even postulated the possibility of conjunctivitis being the only manifestation of this disease. ${ }^{31}$ In a series of five cases, conjunctivitis has been reported as a sole presenting sign of COVID-19, with no other systemic manifestation of the illness. ${ }^{20}$ Our study corroborates the fact that conjunctivitis remains the most common and primary ocular manifestation of this disease.

The varying range of incidence of ocular manifestations in published literature could be due to variable sample size across studies, severity of disease, population characteristics in different geographical regions and the temporal shift of the pandemic. This study exhibits ocular manifestation to be evident in small proportions of group 1 patients as opposed to further less in group 2. However, it was observed that the odds of presentation of ocular manifestations were higher with increasing disease severity in group 1, unlike in group 2, which could be attributed to raised inflammatory markers such as erythrocyte sedimentation rate, $\mathrm{C}$ reactive protein and lactate

\begin{tabular}{|c|c|c|c|c|c|c|c|c|}
\hline Comorbidity & \multicolumn{2}{|c|}{$\begin{array}{l}\text { Total } \\
\text { n (\%) } \\
(\mathbf{N}=\mathbf{2 4 0 0 )}\end{array}$} & \multicolumn{2}{|c|}{$\begin{array}{l}\text { Group } 1 \\
\mathbf{n}(\%) \\
(\mathbf{n}=1200)\end{array}$} & \multicolumn{2}{|c|}{$\begin{array}{l}\text { Group } 2 \\
\mathbf{n}(\%) \\
(\mathbf{n}=1200)\end{array}$} & \multicolumn{2}{|r|}{$P$ value } \\
\hline Present & \multicolumn{2}{|c|}{511 (21.3) } & \multicolumn{2}{|c|}{297 (24.8) } & \multicolumn{2}{|c|}{$214(17.8)$} & \multirow{2}{*}{\multicolumn{2}{|c|}{$<0.001$}} \\
\hline \multirow[t]{3}{*}{ Absent } & \multicolumn{2}{|c|}{$1889(78.7)$} & \multicolumn{2}{|c|}{903 (75.2) } & \multicolumn{2}{|c|}{986 (82.2) } & & \\
\hline & \multicolumn{4}{|c|}{ Group $1(n=1200)$} & \multicolumn{4}{|c|}{ Group $2(n=1200)$} \\
\hline & \multicolumn{2}{|c|}{$\begin{array}{l}\text { With comorbidities } \\
(\mathrm{n}=297)\end{array}$} & \multicolumn{2}{|c|}{$\begin{array}{l}\text { Without comorbidities } \\
(n=903)\end{array}$} & \multicolumn{2}{|c|}{$\begin{array}{l}\text { With comorbidities } \\
(n=214)\end{array}$} & \multicolumn{2}{|c|}{$\begin{array}{l}\text { Without comorbidities } \\
(\mathrm{n}=986)\end{array}$} \\
\hline Ocular manifestation & $\mathbf{n}$ & $\%$ & $n$ & $\%$ & $\mathbf{n}$ & $\%$ & $n$ & $\%$ \\
\hline Present $(n=168)$ & 57 & 19.2 & 87 & 9.6 & 6 & 2.8 & 18 & 1.8 \\
\hline Absent (n=2232) & 240 & 80.8 & 816 & 90.4 & 208 & 97.2 & 968 & 98.2 \\
\hline$P$ value & \multicolumn{4}{|c|}{$<0.001$} & \multicolumn{2}{|c|}{0.415} & & \\
\hline
\end{tabular}


Table 5 Ocular manifestations reported in various studies

\begin{tabular}{|c|c|c|c|c|}
\hline $\begin{array}{l}\text { Serial } \\
\text { number }\end{array}$ & Author & $\begin{array}{l}\text { Patients with ocular manifestations/ } \\
\text { total number of study subjects } \\
\text { (percentage) }\end{array}$ & Ocular manifestations & $\begin{array}{l}\text { Onset of ocular of } \\
\text { manifestations }\end{array}$ \\
\hline 1 & Deng et $\mathrm{al}^{14}$ & $0 / 114$ & $>$ Nil. & - \\
\hline 2 & Guan et $a l^{15}$ & $9 / 1009$ (0.89) & - Conjunctival congestion. & - \\
\hline 3 & Zhang et $a l^{38}$ & $2 / 72(2.8)$ & $\begin{array}{l}\text { Epiphora. } \\
\text { Conjunctival hyperaemia. }\end{array}$ & Days $2-5$ \\
\hline 4 & Chen et al ${ }^{16}$ & $25 / 534(4.7)$ & $\begin{aligned} & \text { Conjunctival congestion. } \\
& \text { Secretion. } \text { S } \\
& \text { Dry eye }(20.97 \%) . \\
& \text { Blurred vision }(12.73 \%) . \\
& \text { Foreign body sensation } \\
& \\
& \text { (11.80\%). } \\
& \text { Ophthalmoplegia. } \\
& \text { Photophobia. }\end{aligned}$ & Days 8-12 \\
\hline 5 & Xia et $\mathrm{al}^{17}$ & $1 / 30(3.3)$ & Conjunctival hyperaemia. & Day 3 \\
\hline 6 & Seah et $a^{18}$ & $0 / 17$ & $>$ Nil. & - \\
\hline 7 & Wu et $a l^{19}$ & $12 / 38(31.6)$ & $\begin{array}{l}\text { Chemosis. } \\
\text { Epiphora. } \\
\text { Conjunctival hyperaemia. } \\
\text { Secretion. }\end{array}$ & - \\
\hline 8 & Zhou et al ${ }^{20}$ & $1 / 67(1.5)$ & - Conjunctival hyperaemia. & - \\
\hline 9 & Singh et $a l^{21}$ & $3.17 \%$ (6 studies, 854 patients) & $>$ Red eye. & Pooled analysis \\
\hline 10 & Current study & $144(12)$ & $\begin{array}{l}\text { Conjunctival congestion. } \\
\text { Burning sensation of eyes. } \\
\text { Foreign body sensation and } \\
\text { irritation of eyes. }\end{array}$ & Days $1-5$ \\
\hline
\end{tabular}

dehydrogenase and consequent to an increased inflammatory reaction in the body with increasing COVID-19 severity. ${ }^{31}$ Of the 17 patients with severe acute respiratory infections, 10 had ocular manifestations and the results were statistically significant at this value. A similar study conducted in Hubei Province, China showed that onethird of patients with COVID-19 had ocular involvement and occurred with greater frequency in patients with more severe disease. ${ }^{20}$

Increased incidence and severity of ocular manifestations in severe disease can be correlated with the immune response of the host. It is likely that the extent of immune response is not equal in all patients due to variability in determinants. ${ }^{30}$ Thus, there is a significant intragroup and intergroup disparity in ocular manifestations. Furthermore, subjects of varying disease severity manifested different signs and symptoms in direct dependence to the systemic severity of COVID-19. A meta-analysis concluded that conjunctivitis in patients with COVID-19 is usually associated with a more severe form of the disease and a worse outcome. ${ }^{24}$ Gulati $e t a l^{22}$ postulated that some forms of conjunctivitis are sustained by an autoimmune mechanism; hence, it may be possible that macrophage activation syndrome also plays a role in the pathogenesis of SARS-CoV-2 conjunctivitis.

Regarding ocular manifestations in patients with coexistent systemic comorbidities in the two groups, it was observed that the probability of the presence of ocular manifestations was 2.019 times higher in group 1 than in group 2; thus, it could be inferred that the presence of systemic comorbidities increases the likelihood of the presence of an ocular involvement. The same can be attributed to an increased frequency of ocular manifestations among elderly patients.

While studies have been conducted to identify the presence of viral RNA from conjunctival swabs via RT-PCR, there has been a lower percentage of positive results, which can be attributed to low viral load below the threshold of test detection. ${ }^{28}$ Interestingly, $\mathrm{Wu}$ et $a l^{19}$ reported that patients with ocular symptoms from COVID-19, compared with patients without ocular manifestations, had higher white cell count and neutrophil count and higher levels of procalcitonin, C reactive protein and lactate dehydrogenase. Thus it can be hypothesised that the presence of ocular manifestations is a result of direct viral multiplication in high titres, as well as an immune-mediated inflammatory reaction to viral antigen. Importantly the conjunctival manifestations of COVID-19 are largely self-limiting. In some cases, the use of ribavirin and ganciclovir as topical therapy was followed by improvement in signs and symptoms. ${ }^{32}$

This study also reports that SARS-CoV-2 can cause conjunctivitis in the early stages of the disease as well as during hospitalisation for severe systemic disease. 
A meta-analysis by Loffredo $e t a l^{33}$ reported that the overall rate of conjunctivitis in confirmed patients with COVID-19 was $1.1 \%$, as compared with $3 \%$ and $0.7 \%$ in severe and non-severe patients, respectively. Furthermore, conjunctivitis is more frequent in severe illness and may be a warning sign of poor outcomes. On the contrary, Huang et $a l^{34}$ reported that 15 (27\%) of the 56 confirmed patients with COVID-19 had aggravated ocular symptoms, out of whom $6(11 \%)$ had prodromal ocular symptoms before disease onset.

There have been concerns regarding the transmission of the virus through tears of patients with COVID-19. A limited number of studies have been conducted where tear samples from infected patients were studied using RT-PCR. ${ }^{356}$ Karimi et $a l^{85}$ found that $7 \%$ of patients had viral RNA in their conjunctival secretions, whereas in a study on Indian patients the authors ${ }^{36}$ found RT-PCR positivity in tears to be $24 \%$. Possible explanation for a lesser potential to detect viral particles in ocular surface and secretions could be due to test sensitivity, timing of sample collection vis-a-vis incubation period, local antimicrobial mechanisms of the conjunctival and ocular surface, collection techniques, and frequent washing of viral particles by tears in the nasolacrimal duct.

It has been shown that SARS-CoV-2 through its spike (S) protein uses human ACE2 receptor to invade susceptible cells. ${ }^{36}$ However, ACE2 is mainly expressed in the retinal pigment epithelium, not in the human conjunctival and corneal epithelium. ${ }^{37}$ We believe this could be the reason for the low viral load and fewer ocular involvement among patients in our study.

To the best of our knowledge, this is the first study to evaluate the ocular manifestations of COVID-19 in a large sample size and provides insights into the clinical presentation and prevalence in association with COVID19. However, the study has certain limitations. There is an obvious scarcity of incontrovertible evidence to guide health policy and patient management since the medical fraternity, researchers and scientists have only recently begun to understand this disease and the interventions required. Therefore, randomised controlled trials with conjunctival swab analysis and better quantitative predictors of viral detection are imperative to understand ocular involvement, manifestations and correlation with severity of COVID-19.

\section{CONCLUSION}

This study attempts to provide a comprehensive report of ocular manifestations in SARS-CoV-2, supported by extensive clinical data and analysis, as a resource for identifying and classifying symptoms and formulation of transmission mitigation strategy. The presence of ocular manifestations with increased frequency in COVID-19 and its direct correlation with severity of systemic disease is a potentially important consideration when evaluating patients with ocular complaints. While examining cases of overt ocular manifestations in patients with an evident systemic viral illness, the ophthalmologist should raise a concern and further rule out COVID-19 with appropriate diagnostic tests. This becomes more important in the scenario of various vaccines being administered by different countries; the testing rates would eventually dip and it is imperative for an ophthalmologist to identify ocular manifestations that raise suspicion for COVID-19. This would aid in making a correct diagnosis, in addition to alleviating the chances of further transmission.

Contributors DSa, DSo: writing - original draft, analysis and interpretation of data, investigation, validation, resources. AN, FK: investigation, resources. SK: writing - review and editing, analysis and interpretation of data. V: analysis and interpretation of data. RRM: conceptualisation and methodology, supervision. BS: conceptualisation and methodology, validation, data curation, writing - review and editing, supervision.

Funding This work was partially supported by the Ruth M Kraeuchi Missouri Endowed Chair Ophthalmology of the University of Missouri, Columbia, Missouri, USA.

Competing interests None declared.

Patient and public involvement Patients and/or the public were not involved in the design, or conduct, or reporting, or dissemination plans of this research.

Patient consent for publication Not required.

Ethics approval Ethical clearance for the study and approval of study protocol were obtained from the Institutional Review Board (IRB-2020/IM0303) and the Institutional Human Ethics Committee (IHEC AllMS, Bhopal). The study protocol adheres to the tenets of the Declaration of Helsinki. Investigators complied with standard universal precautions, according to institutional guidelines, while interacting with study participants.

Provenance and peer review Not commissioned; externally peer reviewed.

Data availability statement Data sharing not applicable as no datasets generated and/or analysed for this study.

Open access This is an open access article distributed in accordance with the Creative Commons Attribution Non Commercial (CC BY-NC 4.0) license, which permits others to distribute, remix, adapt, build upon this work non-commercially, and license their derivative works on different terms, provided the original work is properly cited, appropriate credit is given, any changes made indicated, and the use is non-commercial. See: http://creativecommons.org/licenses/by-nc/4.0/.

\section{ORCID iDs}

Deepak Soni http://orcid.org/0000-0002-4181-8939

Samendra Karkhur http://orcid.org/0000-0002-6991-4746

Rajiv R Mohan http://orcid.org/0000-0002-1857-4200

Bhavana Sharma http://orcid.org/0000-0003-4290-5011

\section{REFERENCES}

1 Hassan SA, Sheikh FN, Jamal S, et al. Coronavirus (COVID-19): a review of clinical features, diagnosis, and treatment. Cureus 2020;12:e7355.

2 Who coronavirus disease (COVID-19) Dashboard. Available: https:// covid19.who.int [Accessed 20 Jan 2021].

3 Morawska L, Cao J. Airborne transmission of SARS-CoV-2: the world should face the reality. Environ Int 2020;139:105730.

4 Rothan HA, Byrareddy SN. The epidemiology and pathogenesis of coronavirus disease (COVID-19) outbreak. J Autoimmun 2020;109:102433.

5 World Health Organisation. Coronavirus disease (COVID-19) pandemic. Available: https://www.who.int/emergencies/diseases/ novel-coronavirus-2019?gclid=CjOKCQjwpNr4BRDYARIsAADIx9wb xH3v2OoRuyfjU9gTM5ENI5xQPbRVeVloaRS4Ig4zYjvKI8DwByga AoLwEALW_wcBAccessed [Accessed 30 May 2021].

6 GOVERNMENT OF INDIA. IndiaFightsCorona COVID-19. Available: https://mygov.in/covid-19Accessed [Accessed 30 May 2021].

7 Clinical management protocol: COVID-19 government of India Ministry of health and family welfare Directorate General of health services (EMR division) version 3 13.06.20. Available: https:// www.mohfw.gov.in/pdf/ClinicalManagementProtocolforCOVID19. pdfAccessed [Accessed 20 Jan 2021]. 
8 Seah I, Agrawal R. Can the coronavirus disease 2019 (COVID-19) affect the eyes? A review of coronaviruses and ocular implications in humans and animals. Ocul Immunol Inflamm 2020;28:391-5.

9 ICMR - Advisory on strategy for COVID-19 testing in India - v6 September 2020. Available: https://covidhelplinebangalore.com/ knowledgebase/advisory-on-strategy-for-covid-19-testing-in-indiaicmr/Accessed [Accessed 20 Jan 2021].

$10 \mathrm{Kubba} H$, Robson AK, Bearn MA. Epiphora: the role of rhinitis. Am J Rhinol 1998;12:273-4.

11 Annamalai S, Kumar NA, Madkour MB, et al. An association between acquired epiphora and the signs and symptoms of chronic rhinosinusitis: a prospective case-control study. Am J Rhinol 2003;17:111-4.

12 Lai C-C, Shih T-P, Ko W-C, et al. Severe acute respiratory syndrome coronavirus 2 (SARS-CoV-2) and coronavirus disease-2019 (COVID-19): the epidemic and the challenges. Int J Antimicrob Agents 2020;55:105924.

13 Gupta N, Praharaj I, Bhatnagar T, et al. Severe acute respiratory illness surveillance for coronavirus disease 2019, India, 2020. Indian J Med Res 2020;151:236-40.

14 Deng C, Yang Y, Chen H. Ocular Dectection of SARS-CoV-2 in 114 cases of COVID-19 pneumonia in Wuhan, China: an observational study (2/19/2020) https://ssrn.com/abstract $=3543587$

15 Guan W-J, Ni Z-Y, Hu Y, et al. Clinical characteristics of coronavirus disease 2019 in China. N Engl J Med 2020;382:1708-20.

16 Chen L, Deng C, Chen X, et al. Ocular manifestations and clinical characteristics of 535 cases of COVID-19 in Wuhan, China: a crosssectional study. Acta Ophthalmol 2020;98:e951-9.

17 Xia J, Tong J, Liu M, et al. Evaluation of coronavirus in tears and conjunctival secretions of patients with SARS-CoV-2 infection. $J$ Med Virol 2020;92:589-94.

18 Seah IYJ, Anderson DE, Kang AEZ, et al. Assessing viral shedding and infectivity of tears in coronavirus disease 2019 (COVID-19) patients. Ophthalmology 2020;127:977-9.

19 Wu P, Duan F, Luo C, et al. Characteristics of ocular findings of patients with coronavirus disease 2019 (COVID-19) in Hubei Province, China. JAMA Ophthalmol 2020;138:575-8.

20 Zhou F, Yu T, Du R, et al. Clinical course and risk factors for mortality of adult inpatients with COVID-19 in Wuhan, China: a retrospective cohort study. Lancet 2020;395:1054-62.

21 Singh G, Sharma PK, Malviya R, et al. Novel corona virus disease (COVID-19) and ophthalmic manifestations: clinical evidences. Dermatol Ther 2020;33:e13814.

22 Choudhary R, Kapoor MS, Singh A, et al. Therapeutic targets of renin-angiotensin system in ocular disorders. J Curr Ophthalmol 2017;29:7-16.
23 Cheema M, Aghazadeh H, Nazarali S, et al. Keratoconjunctivitis as the initial medical presentation of the novel coronavirus disease 2019 (COVID-19). Can J Ophthalmol 2020;55:e125-9.

24 Navel V, Chiambaretta F, Dutheil F. Haemorrhagic conjunctivitis with pseudomembranous related to SARS-CoV-2. Am J Ophthalmol Case Rep 2020;19:100735.

25 Leibowitz HM. The red eye. N Engl J Med Overseas Ed 2000;343:345-51.

26 Azari AA, Barney NP. Conjunctivitis: a systematic review of diagnosis and treatment. JAMA 2013;310:1721-9.

27 Kanski JJ, Bowling B. Kanski's clinical ophthalmology e-book: a systematic approach. Elsevier Health Sciences, 2015.

28 Lu C-W, Liu X-F, Jia Z-F. 2019-nCoV transmission through the ocular surface must not be ignored. Lancet 2020;395:e39.

29 Wang D, Li R, Wang J, et al. Correlation analysis between disease severity and clinical and biochemical characteristics of 143 cases of COVID-19 in Wuhan, China: a descriptive study. BMC Infect Dis 2020;20:519.

30 Bertoli F, Veritti D, Danese C, et al. Ocular findings in COVID-19 patients: a review of direct manifestations and indirect effects on the eye. J Ophthalmol 2020;2020:1-9.

31 Channappanavar R, Perlman S. Pathogenic human coronavirus infections: causes and consequences of cytokine storm and immunopathology. Semin Immunopathol 2017;39:529-39.

32 Gulati A, Pomeranz C, Qamar Z, et al. A comprehensive review of manifestations of novel coronaviruses in the context of deadly COVID-19 global pandemic. Am J Med Sci 2020;360:5-34.

33 Loffredo L, Pacella F, Pacella E, et al. Conjunctivitis and COVID-19: a meta-analysis. J Med Virol 2020;92:1413-4.

34 Huang C, Wang Y, Li X, et al. Clinical features of patients infected with 2019 novel coronavirus in Wuhan, China. Lancet 2020;395:497-506

35 Karimi S, Arabi A, Shahraki T, et al. Detection of severe acute respiratory syndrome Coronavirus-2 in the tears of patients with coronavirus disease 2019. Eye 2020;34:1220-3.

36 Arora R, Goel R, Kumar S, et al. Evaluation of SARS-CoV-2 in tears of patients with moderate to severe COVID-19. Ophthalmology 2021;128:494-503

37 Lu R, Zhao X, Li J, et al. Genomic characterisation and epidemiology of 2019 novel coronavirus: implications for virus origins and receptor binding. Lancet 2020;395:565-74.

38 Zhang X, Chen X, Chen L, et al. The evidence of SARS-CoV-2 infection on ocular surface. Ocul Surf 2020;18:360-2. 